\title{
The Role of Coping Strategies in the Resilience and Well-Being of College Students during COVID-19 Pandemic
}

\author{
Violeta C. Valladolid \\ De La Salle University, Manila, Philippines
}

\section{Article history: \\ Submitted: 19 April 2021 \\ Revised: 30 May 2021 \\ Accepted: 15 June 2021}

\section{Keywords:}

Educational psychology

Resilience

Coping strategy

Academic emotions

Mental well-being

Philippines

ABSTRACT. The study aimed to investigate the relationship between resilience and well-being of college students during the Covid-19 pandemic and to determine the moderating role of coping strategies in this relationship. Resilience was defined based on the concept of Connor and Davidson (2003), who defined it as an individual characteristic that allows an individual to thrive in the face of adversity, coping strategies were categorized into approach or avoidant coping strategies as measured by COPE Brief, and well-being was conceptualized based on Warwick-Edinburgh's concept of mental well-being, interaction with significant people. It included 243 college students enrolled in one of the 12 online social science courses in one college in Metro Manila who were administered through online platform the Warwick-Edinburgh Mental Well-being Scale, Brief COPE, Connor-Davidson Resilience Scale (CD-RISC-10), and Impacts of the COVID-19 Pandemic on Life of Higher Education Students Questionnaire. Results showed a significant relationship between resilience and well-being. Approach coping strategy also showed significant positive relationships with the three criterion variables: academic, social, and mental well-being, indicating that the more a student employs approach coping strategy, the better is his or her academic, social, and mental well-being. On the other hand, the Avoidant coping strategy was negatively only with academic-related emotions, showing that the less the use of the Avoidant coping approach, the more positive are the academic-related emotions felt by students during online classes. However, both coping strategies failed to moderate the relationship between resilience and well-being. It is recommended that schools implement programs and services that will train students on how to cope during pandemic.

\subsection{Introduction}

The COVID-19 crisis has become the most significant public health crisis in the present times. It has particularly affected students' well-being due to the closure of schools, social distancing, and shift to full online or blended learning. Being stuck at home and fearing getting the virus has caused them considerable stress in various ways. -

Studies have shown that students experienced mild to severe anxiety (Cao et al., 2020; Gonzales et al., 2020; Son et al., 2020; Savitsky et al., 2020; Wang \& Zhao, 2020), depression (Salman et al., 2020), loneliness (Labrague et al., 2020), decreased in sleep quality (Marelli, 2021), greater academic and life difficulties (Kecojevic et al., 2020; Mahdy, 2020), and increase in externalizing problems and attention problems (Copeland et al., 2021) during the pandemic. There was also a decrease in social interaction among students since a lot of restrictions were implemented, such as social distancing, prohibition of social gatherings and events, and closure of malls and other recreational venues. Students were forced to be locked down at home and unable to see their friends, classmates, and relatives. The challenges brought about by Covid-19 have, in one way or another, affected every student in the country and globally.

Among the factors that affect students' ability to cope with stress and maintain well-being during these unprecedented times are resilience and coping skills. They have been known as essential strategies to positively recover and manage stressful conditions, adversities, stressful events, and hardships to sustain optimum mental and psychological health. Those who are not prepared with the necessary resilience and coping capabilities are more disposed to encounter negative mental and psychological outcomes (Labrague et al., 2020). Conversely, those who are more resilient and have more effective coping strategies can adapt to life changes and difficulties and keep functioning well - physically, psychologically, and mentally.

While many studies on the effects of the pandemic have been conducted, not many studies were done among Filipino college students. Furthermore, while most studies focused on the relationships among resilience, coping strategies, and psychological well-being among students (Malkoc \& Yalcin, 2015), the dynamics among these factors during the Covid-19 pandemic remain 
unexplored. Furthermore, little attention has been given to the moderating role of coping strategies on the relationship between resilience and well-being.

\subsection{Framework of the Study}

\section{The role of resilience and coping on well-being}

One factor that affects the ability to cope with stress and maintain well-being during hard times is resilience. The American Psychological Association [APA] (2012, p. 2) describes resilience as the "process of adapting well in the face of adversity, trauma, tragedy, threats, or significant sources of stress - such as family and relationship problems, serious health problems, or workplace and financial stressors". Connor-Davidson Resilience Scale (CD-RISC) defines resilience as personal qualities that enable one to thrive in the face of adversity (Connor \& Davidson, 2003). On the other hand, well-being is defined by the Center for Disease Control and Prevention [CDCP], (2018, p. 2) as the "presence of positive emotions and moods (e.g., contentment, happiness), the absence of negative emotions (e.g., depression, anxiety), satisfaction with life, fulfillment and positive functioning". Mental well-being covers two perspectives: (1) subjective experience of happiness (affect) and its satisfaction and life satisfaction (i.e., hedonic perspective), and (2) positive psychological functioning, good relationships with others, and self-realization (i.e., eudaimonic perspective) (Stewart-Brown \& Janmohamed, 2008). While some researchers have debated that a higher level of well-being functions as a predecessor of resilience, indicating that positive emotions facilitate resilience, others have recommended that the relationship between well-being and resilience can also operate in the reverse path, that is, resilience predicting several well-being consequences including depression, job satisfaction, and subjective well-being (Harms et al., 2018). For example, Camitan and Bajin (2021) explored the relationship between well-being and resilience among Filipino adults who experienced nationwide enhanced community quarantine (ECQ) during the COVID-19 pandemic. They found that the five pillars of wellbeing: positive emotions, engagement, relationships, meaning, and accomplishments, were significantly and positively correlated with resilience in quarantined adults. They also found accomplishment to positively predict resilience while negative emotions to negatively predict resilience.

Research studies also established the positive relationship between well-being and resilience. For example, Hartley (2013) found that resilience was more important and operated differently for students with the most psychological distress, indicating that a resilience framework may assist college students with mental health issues in coping more effectively with the complexities of college learning and improving college retention. Mak et al. (2011) found resilience to be considerably and significantly associated with positive perceptions about the self, the world, and the future and lower levels of depression. Similarly, Smith et al. (2016) found that higher personal resilience was associated with greater use of task-oriented coping strategies associated with more adaptive outcomes and less reliance on nonconstructive emotion-oriented strategies, associated with poorer psychological outcomes. Yildirim and Arslan (2020) likewise found that hope and resilience have significant direct effects on psychological health and subjective well-being among adults during the early stage of COVID-19. Thus, it is expected that the higher the level of resilience of students, the better they will be able to manage the stresses they will experience during the pandemic.

Coping is also identified as one of the protective factors against adversity and stressful conditions. It is also found in many research studies to be associated with well-being (Nunes et al., 2016; Ukeh \& Hassan, 2018; Hayat \& Zafar, 2015). Coping is defined as "constantly changing cognitive and behavioral efforts to manage specific external and/or internal demands that are appraised as taxing or exceeding the resources of the person" (Lazarus \& Folkman (1984), in Olusoga et al., 2010, p. 274). There are different types of coping strategies, and the three top common categorizations for coping strategies consist of emotion-focused versus problem-focused coping, approach versus avoidance coping, and cognitive versus behavioral coping (Aazami et al., 2015). Brief-COPE, a scale that measures effective and ineffective ways to cope with a stressful life event, defines coping as "an effort used to minimize distress associated with negative life experiences" (Eisenberg et al., 2012). It identifies two overarching coping styles: (1) Avoidant Coping and (2) Approach Coping. Avoidant coping, characterized by subscales of denial, substance use, venting, behavioral disengagement, self-distraction, and self-blame, was less effective at managing anxiety and associated with poorer physical health. On the other hand, approach coping is identified by active coping, positive reframing, acceptance, seeking emotional support, and seeking informational 
support. It is associated with more helpful responses to adversity (Carver, 1997). Rilveria (2018), in his attempt to develop a Filipino Coping Strategies Scale, identified nine coping strategies that are unique to Filipinos. These include cognitive reappraisal (pagsusuri), social support (paghingi ng tulong), problem-solving (pagtugon), religiosity (pagkarelihiyoso), tolerance (pagtitiis), emotional release (paglabas ng saloobin), overactivity (pagmamalabis), relaxation/recreation (paglilibang), and substance use (pagbibisyo).

Resilient individuals who have adequate coping skills and support systems are less likely to be stressed during adversity. This indicates that adequate coping abilities make an individual more resilient. Secades et al. (2016) showed that resilience scores correlated positively with task-oriented coping and negatively with disengagement- and distraction-oriented coping at the beginning of the last competitive mesocycle and after an important competition. Wu et al. (2020) also found that higher psychological resilience is associated with a better positive coping style among Chinese undergraduate students.

During the Covid-19 pandemic, students employ different coping strategies to deal with the stress and difficulties. For example, students in China sought social support, isolation, mental disengagement, and responsiveness to humanitarian issues, all of which were significantly associated with anxiety levels. The usage of all four coping strategies was higher in the "severe to extreme" group compared to the "normal" and "minimal to moderate" groups (Nurunnabi et al., 2020). In Pakistan, students' most frequent coping strategies were religious/spiritual and acceptance coping (Salman et al., 2020). More than $90 \%$ of the respondents reported that they tried to find comfort in their religion, spiritual beliefs, prayers, or meditation.

\section{Coping strategies as moderating variable}

Many studies have been conducted with coping strategies serving as a moderator variable between different variables, such as between stress and quality of life (Dardas \& Ahmad, 2015), academic performance (Greer et al., 2015), burnout (Noureen et al., 2019; Solberg et al., 2021), cardiovascular reactivity (Cavanagh \& Obasi, 2021), self-leadership (Maykrantz, 2017), and wellbeing (Solberg et al., 2021), between anxiety and self-efficacy (Arora et al., 2021), between bullying and emotional abuse and harassment (Van den Brande et al., 2021), between job insecurity and mental health (Menendez-Espina et al., 2019), between parental efficacy and depressive symptoms (Woodman \& Hauser-Cram, 2012), between negative urgency and psychological distress (AltanAtalay \& Zeytun, 2020), between work-family spillover and subjective well-being (Sirgy et al., 2020), and between illness perception and quality of life (Bazzazian et al., 2010).

However, there were limited studies on the moderating role of coping strategies on the relationships between positive or negative behavior, traits or emotions (e.g., resilience), and outcomes (e.g., well-being) during the COVID pandemic. A study by Arora et al. (2021) concluded that the negative relationship between anxiety and self-efficacy was stronger and more robust at low levels of coping strategy. At the same time, it got considerably weakened at high levels of coping strategy. Kim et al. (2021) also found that overall, participants' well-being significantly decreased during the COVID-19 outbreak. Applying coping strategies, precautionary actions, cognitive evaluation, and behavioral approaches significantly reduced the rate of change in well-being across individuals. Those with higher (vs. lower) observance of precautionary behaviors showed greater decreases in well-being. In contrast, those who employed more cognitive appraisal and behavioral strategies coped with their well-being over time than those who unsuccessfully use these coping strategies.

This study explored the moderating role of coping strategies on the relationship between resilience and well-being among Filipino college students during the COVID 19 pandemic [Figure 1]. It was hypothesized that resilient students would have better psychological outcomes, with approach Coping strategy buffering negative emotions and facilitating positive well-being among students during this crisis. Examining the roles of coping in relation to resilience and well-being is essential to provide school administrators some feedback that they can make to develop a program that will help students maintain their psychological health during the crisis. 


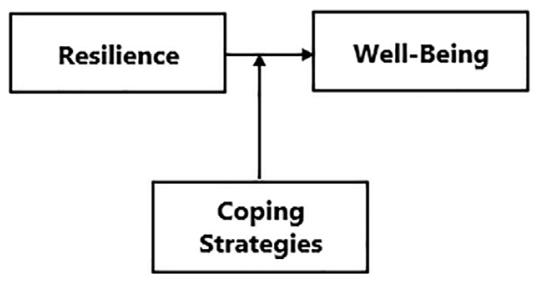

Figure 1: Coping strategy mocerating the relationship between resilience and well-being

\subsection{Methods}

This is a descriptive-correlational study of the relationship between resilience and well-being of college students during the COVID pandemic, with coping strategies as the moderator in the association of the two variables.

The study included 243 college students enrolled in one college in Metro Manila, aged 1825 years old (mean age $=20.28$ ), and enrolled in one of the 12 full-online social science courses during Term 2 of AY 2020-2021 who responded to the online survey. The sample size comprised $73 \%$ of the target sample of 333 students (based on Slovin's formula, with $N=2000$ students enrolled in a total of 50 classes). The online link was given to the faculty of these 12 classes, who then shared the link with the students. More than fifty percent of the participants were male $(53 \%)$. They were enrolled in different academic programs: 83 (34\%) in information technology, 72 (30\%) in arts and design, $38(16 \%)$ in hotel management, $32(13 \%)$ in business and management, and 18 (7\%) in liberal arts courses.

The study made use of the following instruments: Warwick-Edinburgh Mental Well-being Scale (WEMWBS), Brief COPE, Connor-Davidson Resilience Scale (CD-RISC-10), and Impacts of the COVID-19 Pandemic on Life of Higher Education Students Questionnaire.

The Warwick-Edinburgh Mental Well-being Scale (WEMWBS) is composed of 14 positivelystated scales measuring the feeling and functioning aspects of mental well-being. It covers both hedonic and eudaimonic perspectives of mental health, including positive affect (feelings of relaxation, cheerfulness, optimism), gratifying interpersonal relationships, and positive functioning (personal development, energy, competence, clear thinking, self-acceptance, and autonomy). Participants were asked to rate their experiences over the past two weeks using a 5-point scale ("none of time" to "all the time"), giving a minimum total score of 14 and a maximum total score of 70 . A higher WEMWBS score shows a higher level of mental well-being (Tennant et al., 2007).

Brief COPE is designed to measure effective and ineffective ways to cope with a stressful life event, i.e., either approach coping or avoidant coping. Approach coping is described by the subscales of effective coping, positive reframing, preparation, acceptance, soliciting emotional comfort, and exploring informational assistance. In contrast, avoidant coping is characterized by the subscales of denial, substance use, venting, behavioral disengagement, self-distraction, and self-blame. Participants were asked to rate each item (representing a coping strategy) using a 4-point Likert scale ranging from 1 ("I usually don't do this at all") to 4 ("I usually do this a lot"). The higher raw and percentile score indicate the relative preference to that particular coping strategy over the other strategy when experiencing adversity (Eisenberg et al., 2012).

Connor-Davidson Resilience Scale (CD-RISC-10) comprises ten of the original 25 items from the CD-RISC-25 scale and measures resilience or how well an individual is equipped to bounce back after stressful events, tragedy, or trauma. Participants are required to assess each item on a 5-point scale, ranging from 0 (not true of all) to 4 (nearly true all the time). Total scores are based on summing all ten (10) items. A higher score indicates higher resilience (Abilitylab, 2015).

Impacts of the COVID-19 Pandemic on Life of Higher Education Students Questionnaire was developed by the University of Ljubljana, Faculty of Public Administration to determine what student life looked like during the COVID-19 pandemic. For this study, selected items from only four of the seven sections of the questionnaire were adopted, namely: (1) academic life, (2) social life, (3) emotional life, and (4) general circumstances. The academic life items focus on how the Covid-19 
pandemic affected students' performance and expectation; the social life items, on students' extent of online communication with specific people; the emotional life item, on the frequency of the positive emotions felt by the students; and the general circumstances items, on students' worries about short- and long-term future during the pandemic (Aristovnik et al., 2020).

Given that schools were on lockdown and social/physical distancing was imposed during the pandemic, the survey form was shared through an online data collection platform. The students were instructed that their participation in the study was voluntary. There will be no negative consequences if they decide not to participate. Any identifiable or personal information obtained will remain confidential and not be disclosed to any person or organization. Data were analyzed using the descriptive statistics (mean, SD), Pearson correlation, and moderated regression analysis model.

\subsection{Results}

\section{Academic-related emotions}

Descriptive analysis results indicate a moderate level of academic emotions $(M=26.56, S D=$ 6.10) among the students during the COVID pandemic. The students' academic life was filled with both positive and negative emotions during a school lockdown. When asked about how they felt while attending their online classes, students indicated that they "rarely" felt frustrated, anxious, tired, and stressed. At the same time, they occasionally felt joyful, hopeful, excited, and motivated, and also angry and bored. Overall, the most-felt positive emotion since school lockdown was hope $(M=3.24$, $S D=1.00)$ while the most-felt negative emotion was anger $(M=3.27, S D=1.00)$. They rated their academic life/performance as "just the same" before and during a school lockdown.

Table 1. Students' emotions and academic life during school lockdown

\begin{tabular}{|c|c|c|c|c|c|c|c|}
\hline Emotion & M & SD & VI & Academic Life & M & SD & VI \\
\hline Joyful & 3.13 & 0.91 & $\mathrm{~S}$ & $\begin{array}{l}\text { It is more challenging for me to } \\
\text { concentrate during online teaching } \\
\text { compared to face-to-face. }\end{array}$ & 3.98 & 1.03 & A \\
\hline Hopeful & 3.24 & 1.00 & $S$ & $\begin{array}{l}\text { My performance as a learner has } \\
\text { progressed since on-site classes were } \\
\text { discontinued. }\end{array}$ & 3.08 & 0.92 & $\mathrm{~N}$ \\
\hline Excited & 2.94 & 0.95 & $S$ & $\begin{array}{l}\text { I have adjusted well to the current } \\
\text { teaching and learning experience and } \\
\text { practice. }\end{array}$ & 3.50 & 0.89 & A \\
\hline Frustrated & 2.33 & 0.97 & $\mathrm{R}$ & $\begin{array}{l}\text { I can master the knowledge, skills and } \\
\text { competencies taught in an online class. }\end{array}$ & 3.11 & 0.94 & $\mathrm{~N}$ \\
\hline Angry & 3.27 & 1.10 & S & $\begin{array}{l}\text { I can figure out how to do the most } \\
\text { demanding classwork in online classes. }\end{array}$ & 3.45 & 1.00 & A \\
\hline Anxious & 2.21 & 1.12 & $\mathrm{R}$ & $\begin{array}{l}\text { I am more interested and motivated to } \\
\text { study my lessons during the lockdown. }\end{array}$ & 2.76 & 1.12 & $\mathrm{~N}$ \\
\hline Tired & 1.85 & 0.87 & $\mathrm{R}$ & I never skipped my online classes. & 3.81 & 1.23 & A \\
\hline Stressed & 1.92 & 0.97 & $\mathrm{R}$ & $\begin{array}{l}\text { I enjoy doing my assignments and } \\
\text { schoolwork in online classes than in- } \\
\text { classes before. }\end{array}$ & 2.79 & 1.11 & $\mathrm{~N}$ \\
\hline Motivated & 3.12 & 0.93 & $\mathrm{~S}$ & $\begin{array}{l}\text { I spend more time in self-study in online } \\
\text { classes than in face-to-face classes. }\end{array}$ & 3.59 & 1.11 & $A$ \\
\hline Bored & 2.56 & 1.00 & S & $\begin{array}{l}\text { 10. I prefer face-to-face classes more } \\
\text { than online classes. }\end{array}$ & 4.24 & 1.04 & $A$ \\
\hline $\begin{array}{l}\text { Mean (Total } \\
\text { Score) }\end{array}$ & 26.56 & 6.10 & $S^{*}$ & & & & \\
\hline
\end{tabular}

Notes: $\mathrm{VI}=$ Verbal Interpretation; $\mathrm{S}=$ Sometimes; $\mathrm{R}=$ Rarely; $\mathrm{A}=$ Agree; $\mathrm{N}=$ Neutral; * $\mathrm{S}=$ Moderate which indicates that overall, the above emotions were sometimes or moderately felt by students $(M=24.50-34.49)$ 
Furthermore, while they agreed that it was more difficult for them to focus during online classes and would prefer face-to-face classes more than online classes, they also agreed that they have adapted to the new teaching and learning experience, figured out how to do the most difficult classwork in online classes, never skipped their online classes, and spent more time studying in online classes. [Table 1]

\section{Social interaction}

Students' online interaction with significant others was moderate during the pandemic $(M=27.29, S D=5.14)$. While they always communicated online with their close family members and often with their close friends, classmates, friends in school, and social network friends, they have communicated less with their relatives and neighbors during the pandemic (i.e., sometimes). Nevertheless, they said that their social life/interaction was "just the same" during the pandemic as before the crisis. [Table 2].

Table 2. Social interaction of students through online communication during pandemic

\begin{tabular}{lccc}
\hline Significant People & $\mathrm{M}$ & $\mathrm{SD}$ & $\mathrm{VI}$ \\
\hline Close family member/s (parents or siblings) & 4.62 & 0.70 & $\mathrm{~A}$ \\
More distant family member/s (relatives) & 2.86 & 1.19 & $\mathrm{~S}$ \\
Close friend/s & 3.81 & 1.14 & $\mathrm{O}$ \\
Neighbors & 1.98 & 1.19 & $\mathrm{R}$ \\
Classmates & 3.68 & 1.09 & $\mathrm{O}$ \\
Friends in school & 3.54 & 1.24 & $\mathrm{O}$ \\
Teachers & 2.93 & 1.09 & $\mathrm{~S}$ \\
Social network & 3.86 & 1.21 & $\mathrm{O}$ \\
\hline Mean (Total Score) & 27.29 & 5.15 & $\mathrm{~S}^{*}$
\end{tabular}

Notes: $\mathrm{A}=$ Always; $\mathrm{O}=$ Often; $\mathrm{S}=$ Sometimes; $\mathrm{R}=$ Rarely; ${ }^{\mathrm{S}}$ = Moderate which indicates that overall, the students had sometimes or moderate online social interaction with their significant others during the pandemic $(M=19.60-27.59)$

\section{Mental well-being}

Results show that students could adapt to the pandemic to a moderate extent $(M=43.43, S D=$ 10.07). While they most felt optimistic about their future, interested in new things, and loved during this crisis, they also occasionally felt useful, relaxed, confident, cheerful, and good about themselves. Likewise, they sometimes felt close to other people, had the energy to spare, and capable of dealing with problems, thinking clearly, and making up their minds about something.

However, the students experienced different kinds of worries during the pandemic. Overall, they were most worried about their future professional career $(M=4.23, S D=0.97)$ and least concerned about travelling abroad $(M=3.02, S D=1.40)$ during this time. They reported that they "often" felt worried about their life circumstances, particularly their physical health, studies, future education, personal and family finances, family and relationship, professional career in the future, COVID and other similar pandemic, leisure activities, and mental health (Ms ranging from 3.40 to 4.23). Nonetheless, they also believed that their well-being was "just the same" as before the pandemic hit. [Table 3]

\section{Relationships among resilience, coping strategy, and well-being}

Results in Table 4 show significant and positive correlations among the different variables. In particular, resilience was positively and significantly correlated with academic-related emotions, $r(241)=.34, p<.001$; social interaction, $r(241)=.25, p<.001$; and mental well-being, $r(241)=.59, p<.001$. This indicates that students with a high level of resilience felt more positive emotions while attending online classes, indulged in online interaction, and had a high mental well-being level. Approach coping strategy also showed significant positive relationships with the three criterion variables: academic, $r(241)=.21, p=.001$; social, $r(241)=.26, p<.001$; and mental well-being, $r(241)=.56, p<.001$. 
This indicates that the more a student employs the approach coping strategy, the better is his or her academic, social, and mental well-being. On the other hand, an avoidant coping strategy was associated only with academic-related emotions. The correlation coefficient was negative, $r(241)$ $=-0.24, p<.001$. This shows that the less the use of the avoidant coping approach, the more positive are the academic-related emotions felt by students during online classes.

Table 3. Students' feelings and worries during the pandemic

\begin{tabular}{lccc|lccc}
\hline Feelings During Pandemic & M & SD & VI & Worries & M & SD & VI \\
\hline Optimistic about the future & 3.52 & 1.01 & $\mathrm{O}$ & Personal physical health & 3.65 & 1.09 & $\mathrm{O}$ \\
Useful & 3.10 & 0.94 & $\mathrm{~S}$ & Studying issues & 3.98 & 0.99 & $\mathrm{O}$ \\
Relaxed & 2.80 & 0.99 & $\mathrm{~S}$ & Future education & 4.08 & 0.99 & $\mathrm{O}$ \\
Interested in other people & 2.90 & 1.03 & $\mathrm{~S}$ & Personal/family finances & 3.53 & 1.24 & $\mathrm{O}$ \\
Having the energy to spare & 2.95 & 1.03 & $\mathrm{~S}$ & Family and relationship & 3.50 & 1.14 & $\mathrm{O}$ \\
Dealing with problems well & 3.06 & 0.95 & $\mathrm{~S}$ & Future professional career & 4.23 & 0.97 & $\mathrm{O}$ \\
Thinking clearly & 3.14 & 0.92 & $\mathrm{~S}$ & COVID or similar pandemic & 3.91 & 1.04 & $\mathrm{O}$ \\
Good about myself & 3.05 & 1.04 & $\mathrm{~S}$ & Leisure activities & 3.40 & 1.11 & $\mathrm{O}$ \\
Close to other people & 3.07 & 0.99 & $\mathrm{~S}$ & Traveling abroad & 3.02 & 1.40 & $\mathrm{~S}$ \\
Feeling confident & 2.93 & 1.01 & $\mathrm{~S}$ & Mental health issues & 3.79 & 1.27 & $\mathrm{O}$ \\
Able to make up my mind & 3.26 & 0.97 & $\mathrm{~S}$ & & & & \\
Loved & 3.46 & 1.09 & $\mathrm{O}$ & & & & \\
Interested in new things & 3.51 & 1.07 & $\mathrm{O}$ & & & &
\end{tabular}

Notes: $\mathrm{O}=$ Often; $\mathrm{S}=$ Sometimes; ${ }^{*} \mathrm{~S}=$ Moderate which indicates that overall, the students sometimes or moderately experienced the above feelings during the pandemic $(M=34.30-44.29)$

Table 4. Correlation coefficient among variables

\begin{tabular}{lll}
\hline Relationships Between Variables & $\mathbf{r}$ & p-value \\
\hline Resilience vs. Well-Being & & \\
Resilience vs. Academic Emotions & $0.34^{\star * *}$ & $<.001$ \\
Resilience vs. Social Interaction & $0.25^{\star * *}$ & $<.001$ \\
Resilience vs. Mental Well-Being & $0.59^{\star * *}$ & $<.001$ \\
Coping Strategy vs. Well-Being & & \\
Approach vs. Academic Emotions & $0.21^{\star * *}$ & .001 \\
Approach vs. Social Interaction & $0.26^{\star * *}$ & $<.001$ \\
Approach vs. Mental Well-Being & $0.56^{\star * *}$ & $<.001$ \\
Avoidant vs. Academic Emotions & $-0.24^{\star * *}$ & $<.001$ \\
Avoidant vs. Social Interaction & 0.11 & .07 \\
Avoidant vs. Mental Well-Being & -0.01 & .90 \\
Resilience vs. Coping Strategy & & $<.001$ \\
Resilience vs. Approach & $0.54^{* * *}$ & .88 \\
Resilience vs. Avoidant & 0.01 & \\
\hline
\end{tabular}




\section{Moderating role of coping strategy}

A series of a moderated regression analysis model was conducted to test the hypotheses that there are significant relationships between resilience and academic-related emotions, social interaction, and mental well-being among students during the pandemic, with coping strategy serving as moderator. Following an established process, measures of resilience and coping were focused on maximizing understanding and interpretability and minimizing possible complications with multicollinearity (Dardas \& Ahmad, 2015).

Moderation was studied by creating two regression equations that involved resilience, two coping strategies, and a multiplicative term signifying the relations between resilience and each coping strategy. This was done for each dependent variable, namely academic-related emotions, social interaction, and mental well-being. Thus, six models were tested separately.

Tables 5 to 7 show that resilience has a significant direct effect on students' academic, social and mental well-being. Approach coping strategy has a significant direct effect on social and mental wellbeing but not on students' academic emotions. In contrast, the avoidant coping strategy showed a significant direct effect on academic emotions.

Table 5. Moderated model regression analysis for the two coping strategies (Academic-related emotions as dependent variable)

\begin{tabular}{lccccc}
\hline & Coefficients & SE & t Stat & p-value & Adj R $^{2}$ \\
\hline Intercept & 26.64 & 0.40 & 66.02 & .000 & 0.11 \\
RES-CENTERED & 0.27 & 0.06 & 4.36 & .000 & \\
APPROACH-CENTERED & 0.02 & 0.06 & 0.41 & 0.68 & \\
\hline RES x APPROACH & -0.002 & 0.01 & -0.45 & 0.65 & \\
\hline & Coefficients & SE & t Stat & p-value & Adj R 2 \\
\hline Intercept & 26.57 & 0.36 & 74.66 & .000 & 0.17 \\
RES-CENTERED & 0.29 & 0.05 & 5.83 & .000 & \\
AVOIDANT-CENTERED & -0.24 & 0.06 & -4.22 & .000 & \\
\hline RES x AVOIDANT & -0.013 & 0.007 & -1.60 & .1105 & \\
\hline
\end{tabular}

$* \leq 0.05$

Table 6. Moderated model regression analysis for the two coping strategies (Social interaction as dependent variable)

\begin{tabular}{lccccc}
\hline & Coefficients & SE & t Stat & p-value & Adj R \\
\hline Intercept & 27.42 & 0.35 & 79.26 & .000 & 0.07 \\
RES-CENTERED & 0.10 & 0.05 & 1.97 & .05 & \\
APPROACH-CENTERED & 0.12 & 0.05 & 2.25 & .03 & \\
\hline RES x APPROACH & -0.004 & 0.005 & -0.95 & .34 & \\
\hline & Coefficients & SE & t Stat & p-value & Adj R \\
\hline Intercept & 27.29 & 0.32 & 85.55 & .000 & 0.06 \\
RES-CENTERED & 0.18 & 0.04 & 3.97 & .000 & \\
AVOIDANT-CENTERED & 0.09 & 0.05 & 1.78 & .077 & \\
\hline RES x AVOIDANT & -0.004 & 0.007 & -0.70 & .49 & \\
\hline$\leq 0.05$
\end{tabular}

* $\leq .05$ 
Furthermore, results showed that the approach coping strategy failed to moderate the relationships between resilience and the three dependent variables. This is also true for the avoidant coping strategy, which shows that both approach and avoidant coping strategy did not moderate the relationships between resilience and academic emotions and social interaction. This indicates that the relationship between resilience and well-being will not be affected by the coping strategy employed.

Table 7. Moderated model regression analysis for the two coping strategies (Mental well-being as dependent variable)

\begin{tabular}{lccccc}
\hline & Coefficients & SE & t Stat & p-value & Adj R $^{2}$ \\
\hline Intercept & 27.42 & 0.35 & 79.26 & .000 & 0.07 \\
Res-Centered & 0.10 & 0.05 & 1.97 & .05 & \\
Approach-Centered & 0.12 & 0.05 & 2.25 & .03 & \\
RES X APPROACH & -0.004 & 0.005 & -0.95 & 0.34 & \\
\hline & Coefficients & SE & t Stat & p-value & Adj R \\
\hline Intercept & 43.43 & 0.53 & 82.73 & .000 & 0.34 \\
RES-CENTERED & 0.82 & 0.07 & 11.20 & .000 & \\
AVOIDANT-CENTERED & -0.03 & 0.09 & -0.30 & .76 & \\
RES x AVOIDANT & -0.014 & 0.011 & -1.24 & .21 & \\
\hline
\end{tabular}

* $\mathrm{p} \leq .05$

\subsection{Discussion}

The purpose of this study was to investigate the relationships between resilience and some measures of well-being of college students during the Covid-19 pandemic and to determine the moderating role of coping strategies in these relationships. Results of the study confirmed the positive relationship between resilience and well-being. However, the relationship was not moderated by the coping strategy employed. The finding of a positive correlation between resilience and well-being is consistent with relevant studies which reported resilience as contributing to one's positive wellbeing (Malkoc \& Yalcin, 2015; Souri \& Hasanirad, 2011; Chow et al., 2018; Yildirim \& Arslan, 2020; Konaszewski et al., 2021; Chen, 2016). -

Furthermore, the approach coping strategy showed a significant relationship with well-being measures. The avoidant coping strategy was associated only with academic-related emotion, indicating that students who employ less negative coping strategies, such as denial, substance use, venting, behavioral disengagement, self-distraction, and self-blame, are more likely to have positive emotions while attending online classes. These findings are consistent with previous studies. For example, Gustems-Carnicer and Calderon (2013) found approach coping strategies such as problem-solving in teacher education students beneficial for depression, phobic anxiety, and overall psychological distress, while cognitive avoidance coping was associated with a greater presence of psychological symptoms indicating distress. Furthermore, behavioral avoidance strategies were associated with negative psychological well-being.

The study also found a positive correlation between resilience and approach coping strategy, indicating that resilient individuals employ positive coping strategies. This finding is also congruent with other studies that showed resilience correlating positively with a positive coping strategy. For example, a study by Wu et al. (2020) among Chinese students showed that three factors of psychological resilience, namely, mood control, self-plasticity, and coping flexibility, were all significant factors for positive coping styles, indicating that higher psychological resilience is associated with a better positive coping style. Hurley (2018) also found that greater resilience among 
young adolescents was associated with problem-focused and emotion-focused coping strategies than avoidant coping strategies. Moreover, those with higher levels of depression were less resilient and involved in more avoidant coping strategies. In contrast, those who employed more problemfocused coping strategies reported less depression.

However, this present study showed that both approach and avoidant coping strategies did not moderate the relationships between resilience and well-being. While previous literature showed the moderating role of some coping strategies on the relationship between resilience, stress, burnout, and well-being or quality of life (Dardas \& Ahmad, 2015; Connor-Smith \& Compas, 2002; Malkoc \& Yalcin, 2015; Konaszewski et al., 2021), there were also some studies that support the result of this study. For example, Kirsch (2014) found that neither adaptive nor maladaptive coping styles moderated the significant predictive relationship between body dissatisfaction and disordered eating attitudes when adjusting for disordered eating attitudes and BMI. Likewise, Bonner (2015) found that coping diversity did not correspond with measures of perceived stress, mental health, physical health, or the primary method of measuring coping diversity. Overall, high levels of perceived stress were linked to poor and more reduced mental and physical health. These relationships were not, however, moderated by coping self-efficacy or coping diversity.

\subsection{Conclusion}

The findings of the study provide insights on the contribution of resilience in maintaining the well-being of college students during the time of the Covid-19 pandemic and the importance of a positive coping strategy to better well-being. While the study did not establish the moderating role of coping strategy in the relationship, it positively linked resilience and well-being.

The study results will provide the empirical basis on the importance of monitoring the wellbeing of college students and developing their resilience and positive coping strategy in this time of crisis. It is recommended that school administrators need to design and implement student programs and services that will train students how to recreate or adjust stressful conditions, difficulties, and trauma through active and positive coping rather than by wallowing in negative feelings and indulging in dangerous activities. Studies have shown that students who participated in a campus wellness program were less affected by COVID specific to internalizing and adopting to symptoms and attention problems than those who were not enrolled in the program (Copeland et al., 2021). Student services are important at this time, especially for students at risk of mental health problems, who have difficulty coping, and are prone to self-harm. This is also important, especially now that high levels of negative emotions and relatively low levels of positive emotions and many worries have been experienced by the students, which will have specific short- and long-term impacts on students' education and mental health. As Aristovnik (2020, p. 13) said, "the accompanying effects of COVID-19 will continue to profoundly influence students' emotional well-being... (and) this implies that government, health professionals, higher education institutions, student organizations, and NGOs should all cooperate on the process of creating suitable and effective psychological and financial assistance for students".

Some limitations and constraints must be recognized when translating the outcomes of this study. This study was analyzed generally and with a limited sample. It would be good to include more respondents and to include other variables in the analysis, such as gender and type of school. This is to determine whether male and female students and whether students from public and private schools would react differently during stressful times - who are more resilient, what type of coping strategies they employ, and how they are doing academically, socially, and mentally during this pandemic. Furthermore, more specific coping strategies should be included in the study to determine which coping strategies will moderate the relationship. Nevertheless, the results of this study will be relevant for schools in planning their programs to help students thrive in this pandemic.

\section{REFERENCES}

Aazami, S., Shamsuddin, K., Akmal, S. (2015). Examining behavioral coping strategies as mediators between workfamily conflict and psychological distress. The Scientific World Journal. https://doi.org/10.1155/2015/343075 Abilitylab. (2015). Connor-Davidson Resilience Scale 10 Item. https://www.sralab.org/rehabilitation-measures/ connor-davidson-resilience-scale-10-item 
Altan-Atalay, A., \& Zeytun, D. (2020). The association of negative urgency with psychological distress: Moderating role of proactive coping strategies. The Journal of Psychology, 154 (7), 487-498. https://doi.org/10.1080/002 23980.2020.1784824

American Psychological Association (APA). (2012). Building your resilience. https://www.apa.org/topics/resilience

Aristovnik, A., Keržič, D., Ravšelj, D., Tomaževič, N., \& Umek, L. (2020). A global student survey "Impacts of the covid-19 pandemic on life of higher education students". Methodological Framework. https://doi. org/10.20944/preprints202008.0246.v1

Arora, S., Chaudhary, P. \& Singh, R.K. (2021). Impact of coronavirus and online exam anxiety on self-efficacy: The moderating role of coping strategy. Interactive Technology and Smart Education, 21. https://doi.org/10.1108/ ITSE-08-2020-0158

Bazzazian, S., Besharat, M., Bahrami-Ehsan, H., \& Rajab, A. (2010). The moderating role of coping strategies in the relationship between illness perception, quality of life, and $\mathrm{Hbalc}$ in patients with Type I diabetes. Iranian Journal of Endocrinology and Metabolism (IJEM), 12(3), 213-221. https://www.sid.ir/en/journal/ViewPaper. aspx?id $=259584$

Bonner, C.F. (2015). Moderating effects of coping self-efficacy and coping diversity in the stress health relationship in African American college students. [Doctoral dissertation, Old Dominion University]. https://digitalcommons. odu.edu/cgi/viewcontent.cgi?article=1250\&context=psychology_etds

Camitan, D. S., 4th, \&Bajin, L. N. (2021). The importance of well-being on resiliency of Filipino adults during the COVID-19 Enhanced Community Quarantine: A necessary condition Analysis. Frontiers in Psychology, 12, 558930. https://doi.org/10.3389/fpsyg.2021.558930

Cao, W., Fang, Z., Hou, G., Han, M., Xu, X., Dong, J., \& Zheng, J. (2020). The psychological impact of the COVID-19 epidemic on college students in China. Psychiatry Research, 287, 112934. https://doi.org/10.1016/j. psychres.2020.112934

Carver, C. S. (1997). You want to measure coping, but your protocol's too long: Consider the BRIEF COPE. International Journal of Behavioral Medicine, 4(1), 92-100. https://doi.org/10.1207/s15327558ijbm0401_6

Cavanagh, L., \& Obasi, E.M. (2021). The moderating role of coping style on chronic stress exposure and cardiovascular reactivity among African American emerging adults. Prevention Science, 22, 357-366. https://doi.org/10.1007/ s11121-020-01141-3

Center for Disease Control and Prevention (CDCP). (2018, October 31). Well-being concepts. https://www.cdc.gov/ hrqol/wellbeing.htm

Chen, C. (2016). The role of resilience and coping styles in subjective well-being among Chinese university students. Asia-Pacific Education Researcher, 25(3), 377-387. https://doi.org/10.1007/s40299-016-0274-5

Chow, K.M., Tang, W.K.F., Chan, W.H.C., Sit, W.H.J, Choi, K.C., \& Chan, S. (2018). Resilience and well-being of university nursing students in Hong Kong: A cross-sectional study. BMC Medical Education, 18(1), 13. https://doi. org/10.1186/s12909-018-1119-0

Connor, K.M., \& Davidson, J.R.T. (2003). Development of a new resilience scale: The Connor-Davidson Resilience Scale (CD-RISC). Depression \& Anxiety, 18(2), 76-82. https://doi.org/10.1002/da.10113

Connor-Smith, J.K., \& Compas, B.E. (2002). Vulnerability to social stress: Coping as a mediator or moderator of sociotropy and symptoms of anxiety and depression. Cognitive Therapy and Research, 26(1), 39-55. https:// doi.org/10.1023/A:1013889504101

Copeland, W.E., McGinnis, E., Bai, Y., Adams, Z., Nardone, H., Devadanam, V., Rettew, J., \& Hudziak, J.J. (2021). Impact of COVID-19 pandemic on college student mental health and wellness. Journal of the American Academy of Child \& Adolescent Psychiatry, 60(1), 134-141. https://doi.org/10.1016/j.jaac.2020.08.466.

Dardas, L., \& Ahmad, M. (2015). Coping strategies as mediators and moderators between stress and quality of life among parents of children with autistic disorder. Stress and Health, 31(1), 5-12. https://doi.org/10.1002/ smi.2513

Eisenberg, S. A., Shen, B. J., Schwarz, E. R., \& Mallon, S. (2012). Avoidant coping moderates the association between anxiety and patient-rated physical functioning in heart failure patients. Journal of Behavioral Medicine, 35(3), 253-261. https://doi.org/10.1007/s10865-011-9358-0

Gonzales, P.O., Gomez, A.P., Irurtia, M.J., \& Garcia, R.L. (2020). Psychological effects of the COVID-19 outbreak and lockdown among students and workers of a Spanish university. Psychiatry Research, 290. https://doi. org/10.1016/j.psychres.2020.113108

Greer, T.M., Ricks, J., \& Baylor, A.A. (2015). The moderating role of coping strategies in understanding the effects of intragroup race-related stressors on academic performance and perceived stress for African American students. Journal of Black Psychology, 41(6), 565-585. https://doi.org/10.1177/0095798414560018

Gustems-Carnicer, J., \& Calderón, C. (2013). Coping strategies and psychological well-being among teacher education students: Coping and well-being in students. European Journal of Psychology of Education, 28(4), 1127-1140. https://doi.org/10.1007/s10212-012-0158-x

Harms, P. D., Brady, L., Wood, D., \& Silard, A. (2018). Resilience and well-being. Handbook of Well-Being. Salt Lake City, UT: DEF Publishers. https://www.nobascholar.com/chapters/4/download.pdf

Hartley, M. T. (2013). Investigating the relationship of resilience to academic persistence in college students with mental health issues. Rehabilitation Counseling Bulletin, 56(4), 240-250. https://doi.org/10.1177/0034355213480527 
Hayat, I., \& Zafar, M. (2015). Relationship between psychological well-being and coping strategies among parents with down syndrome children. International Journal of Humanities and Social Science, 5(7), 109-117. http:// www.ijhssnet.com/journals/Vol_5_No_7_1_July_2015/12.pdf

Hurley, L.N. (2018). The relationship between resilience, coping, and social media. (Unpublished Thesis, Eastern Illinois University). https://thekeep.eiu.edu/cgi/viewcontent.cgi?article=4680\&context=theses

Kecojevic, A., Basch, C.H., Sullivan, M., \& Davi, N.K. (2020). The impact of the COVID-19 epidemic on the mental health of undergraduate students in New Jersey, cross-sectional study. PLOS ONE, 15(9). https://doi. org/10.1371/journal.pone.0239696

Kim, J.H., Shim, Y., Choi, I., \& Choi, E. (2021). The role of coping strategies in maintaining well-Being during the COVID-19 outbreak in South Korea. Social Psychological and Personality Science. https://doi. org/10.1177/1948550621990595

Kirsch, A. C. (2014). Examining the moderating role of specific coping strategies on the relationship between body image and eating disorders in college-aged women. [Master's thesis, Loyola University Chicago]. https:// ecommons.luc.edu/cgi/viewcontent.cgi?article $=3239 \&$ context=luc_theses

Konaszewski K., Niesiobędzka M., \& Surzykiewicz J. (2021). Resilience and mental health among juveniles: Role of strategies for coping with stress. Health Qual Life Outcomes, 19(1), 58. https://doi.org/10.1186/s12955-02101701-3

Labrague, L.J., de los Santos, J.A.A., \& Falguera, C.C. (2020). Social and emotional loneliness among college students during the COVID 19 pandemic: The predictive role of coping behaviors, social support, and personal resilience. Perspective Psychiatric Care, 1 -7. https://doi.org/10.21203/rs.3.rs-93878/v1

Mahdy, M. A. A. (2020). The impact of COVID-19 pandemic on the academic performance of veterinary medical students. Frontiers in Veterinary Science.7:594261. https://doi.org/10.3389/fvets.2020.594261

Mak, W.W.S., Ng, I.S.W., \& Wong, C.C.Y. (2011). Resilience: Enhancing well-being through the positive cognitive triad. Journal of Counseling Psychology, 58(4), 610-617. https://doi.org/10.1037/a0025195

Malkoc, A., \& Yalcin, I. (2015). Relationships among resilience, social support, coping, and psychological well-being among university students. Turkish Psychological Counseling and Guidance Journal, 5 (43) 35-43. http:// turkpdrdergisi.com/index.php/pdr/article/view/4

Marelli, S., Castelnuovo, A., Somma, A., Castronovo, V., Mombelli, S., Bottoni, D., Leitner, C., Fossati, A., \& FereniStrambi, L. (2021). Impact of COVID-19 lockdown on sleep quality in university students and administration staff. Journal of Neurology, 268, 8-15. https://doi.org/10.1007/s00415-020-10056-6

Maykrantz, S.A. (2017). The moderating role of coping skills on the relationship between self-leadership and stress among college students. [Doctoral dissertation University of Maryland Eastern Shore]. ProQuest LLC. https:// eric.ed.gov/?id=ED580451

Menéndez-Espina S., Llosa J.A., Agulló-Tomás E., Rodríguez-Suárez J., Sáiz-Villar, R., \& Lahseras-Díez, H. F. (2019). Job insecurity and mental health: The moderating role of coping strategies from a gender perspective. Frontiers in Psychology.10:286. https://doi.org/10.3389/fpsyg.2019.00286

Noureen, A., Shah, A. A., \& Shah, M.A. (2019). The moderating role of coping strategies in occupational stress and burnout in mental health practitioners in Pakistan. Clinical and Counselling Psychology Review, 1(1), $28-43$. https://doi.org/10.32350/ccpr.11.03

Nunes, R.P., de Melo, R.L.P., da Silva-Júnior, E.G., \& do Calmo-Eulalio, M. (2016). Relationship between coping and subjective well-being of elderly from the interior of the Brazilian Northeast. Psicologia Reflexão e Crítica, 29(33), 1-8. https://doi.org/10.1186/s41155-016-0032-x

Nurunnabi M., Hossain S.F.A.H., Chinna K., Sundarasen, S., Khoshaim, H.B., Kamaludin, K., Baloch, G.M., Sukayt, A., \& Shan, X. (2020). Coping strategies of students for anxiety during the COVID-19 pandemic in China: A crosssectional study. F1000Research, 9, 1115. https://doi.org/10.12688/f1000research.25557.1

Olusoga, P., Butt, J., Maynard, I., \& Hays, K. (2010). Stress and coping: A study of world-class coaches. Journal of Applied Sport Psychology, 22, 274-293. https://doi.org/10.1080/10413201003760968

Rilveria, J.R.C. (2018). The Development of the Filipino coping strategies scal. Asia-Pacific Social Science Review 18(1), 111-126.

Salman, M., Asif, N., Mustafa, Z., Khan, T., Shehzadi, N., Tahir, H., Raza, M.H., Khan, M.T., Hussain, K., Khan, Y.H. Butt, M.H., \& Mallhi, T. (2020). Psychological impairment and coping strategies during the COVID-19 pandemic among students in Pakistan: A cross-sectional analysis. Disaster Medicine and Public Health Preparedness, 1-7. https://doi.org/10.1017/dmp.2020.397

Savitsky, B., Findling, Y., Ereli, A., \& Hendel, T. (2020). Anxiety and coping strategies among nursing students during the Covid-19 pandemic. Nurse Education in Practice, 46, 102809. https://doi.org/10.1016/j.nepr.2020.102809

Secades, X. G., Molinero, O., Salguero, A., Barquín, R. R., de la Vega, R., \& Márquez, S. (2016). Relationship between resilience and coping strategies in competitive sport. Perceptual and Motor Skills, 122(1), 336- 349. https:// doi.org/10.1177/0031512516631056

Sirgy, M.J., Lee, D. J., Park, S., Joshanloo, M., \& Kim, M. (2020). Work-family spillover and subjective well-being: The moderating role of coping strategies. Journal of Happiness Studies, Springer, 21(8), 2909-2929. https://doi. org/10.1007/s10902-019-00205-8

Smith, M.M., Saklofske, D., Keefer, K.V., \& Tremblay, P.F. (2016). Coping strategies and psychological outcomes: The moderating effects of personal resiliency. The Journal of Psychology Interdisciplinary and Applied 150(3), 318331. https://doi.org/10.1080/00223980.2015.1036828 
Solberg Ø., Sengoelge M., Nissen A., \& Saboonchi F. (2021). Coping in limbo? The moderating role of coping strategies in the relationship between post-migration stress and well-being during the asylum-seeking process. International Journal of Environmental Research and Public Health, (18)3. https://doi.org/10.3390/ ijerph18031004

Son, C., Hegde, S., Smith, A., Wang, X., \& Sasangohar, F. (2020). Effects of COVID-19 on college students' mental health in the United States: Interview survey study. Journal of Medical Internet Research; 22(9): e21279. https:// doi.org/10.2196/preprints.21279

Souri, H., \& Hasanirad, T. (2011). Relationship between resilience, optimism and psychological well-being in students of medicine. Procedia - Social and Behavioral Sciences 30, 1541 - 1544. https://doi.org/10.1016/j. sbspro.2011.10.299

Stewart-Brown, S., \& Janmohamed, K. (2008). Warwick-Edinburgh Mental Well-being Scale (WEMWBS): User guide version 1. http://www.mentalhealthpromotion.net/resources/user-guide.pdf

Tennant, R., Hiller, L., Fishwick, R., Platt, S., Joseph, S., Weich, S., Parkinson, J., Secker, J., \& Stewart-Brown, S. (2007). The Warwick-Edinburgh Mental Well-Being Scale (WEMWBS): Development and validation. Health and Quality of Life Outcomes, 5(63). https://doi.org/10.1186/1477-7525-5-63

Ukeh M.I., \& Hassan A.S. (2018). The impact of coping strategies on psychological well-being among students of Federal University, Lafia, Nigeria. Journal of Psychology and Psychotherapy, 8(5), 1-6. https://doi. org/10.4172/2161-0487.1000349

Van den Brande, W., Bernstein, C., Reknes, I., \& Baillien, E. (2021). The moderating effects of coping mechanisms and resources in the context of workplace bullying, emotional abuse and harassment. Pathways of Job-related Negative Behaviour, 153-176. https://doi.org/10.1007/978-981-10-6173-8_7-1

Wang, C., \& Zhao, H. (2020). The impact of COVID-19 on anxiety in Chinese university students. Frontiers in Psychology. https://doi.org/10.3389/fpsyg.2020.01168

Woodman, A., \& Hauser-Cram, P. (2012). The role of coping strategies in predicting change in parenting efficacy and depressive symptoms among mothers of adolescents with developmental disabilities. Journal of Intellectual Disability Research. https://doi.org/10.1111/j.1365-2788.2012.01555.x

Wu, Y., Yu, W., Wu, X., Wan, H., Wang, Y., \& Lu, G. (2020). Psychological resilience and positive coping styles among Chinese undergraduate students: A cross-sectional study. BMC Psychology, 8, 79. https://doi.org/10.1186/ s40359-020-00444-y

Yıldırım, M., \& Arslan, G. (2020). Exploring the associations between resilience, dispositional hope, preventive behaviors, subjective well-being, and psychological health among adults during an early stage of COVID-19. Current Psychology. https://doi.org/10.1007/s12144-020-01177-2

\section{Correspondence:}

VIOLETA C. VALLADOLID

violeta.valladolid@dlsu.edu.ph

https://orcid.org/0000-0002-1541-0470 